Citation for published version:

Craig Bourne, Emily Caddick Bourne, and Clare Jarmy, 'The Basis of Correctness in the Religious Studies Classroom', Journal of Philosophy of Education, Vol. 50 (4): 669-688, November 2016.

\title{
DOI:
}

https://doi.org/10.1111/1467-9752.12166

\section{Document Version:}

This is the Accepted Manuscript version.

The version in the University of Hertfordshire Research Archive may differ from the final published version.

\section{Copyright and Reuse:}

This article may be used for non-commercial purposes in accordance with Wiley Terms and Conditions for SelfArchiving.

\section{Enquiries}

If you believe this document infringes copyright, please contact the Research \& Scholarly Communications Team at rsc@herts.ac.uk 


\section{The Basis of Correctness in the Religious Studies Classroom}

Craig Bourne (University of Hertfordshire), Emily Caddick Bourne (University of Cambridge) \& Clare Jarmy (Bedales School and UCL Institute of Education)

\section{Abstract}

What is it that makes a student's answer correct or incorrect in Religious Studies? In practice, the standards of correctness in the RS classroom are generally applied with relative ease by teachers and students. Nevertheless, they are problematic. We shall argue that correctness does not come from either the students or the teacher believing that what has been said is true. This raises the question: what is correctness, if it does not come down to truth? We propose, and examine, three rival solutions, each of which, to an extent, rationalises a fairly natural response to the problem. The first, the elliptical approach, says that correct contributions have some tacit content: they are elliptical for true sentences about beliefs (e.g. a sentence of the form 'Christians believe that...'). The second, the imaginative approach, seeks to replace appeals to truth and belief with an appeal to imagination, treating RS as a 'game of make-believe' in which teachers and students imaginatively engage with certain worldviews. The third, the institutional approach, locates the root of correctness in the practices of the RS institution, which include making endorsements of some judgements and not others. We show that the first of our proposed approaches encounters a number of significant objections. We find the second of our proposed approaches to be better, but the third is the most attractive, providing a direct, intuitive and comprehensive route through the problem of correctness. 


\section{The Basis of Correctness in the Religious Studies Classroom}

The question 'How do you assess that?' is one with which Religious Studies teachers will be very familiar, whether from students who contest that 'everything is a matter of faith' or parents who question how religion can be something you get right or wrong. But despite such questions, what is clear is that there are some standards for what counts as a correct contribution in the RS classroom. ${ }^{1}$ To see this, consider the following two sets of sentences:

Set 1

Three days after his death, Jesus rose from the dead

Jesus has fewer arms than Lord Shiva

God is omnipotent

The Prophet Muhammad (pbuh) is the last prophet of God

Set 2

Three days after his death, Jesus went to the moon

Jesus has more legs than Lord Shiva

God lives in the sky

\footnotetext{
${ }^{1}$ We take Religious Studies to be the subject which aims to provide students with an understanding of what beliefs and practices are involved in particular religious worldviews, and how these worldviews compare to one another, without an objective of students acquiring the beliefs and practices of any particular worldview. Another name sometimes given to this subject is 'Religious Education', but we prefer not to use this term as it may invite a reading connoting religious instruction.
} 
The Prophet Muhammad (pbuh) is the first prophet of God

Intuitively, the sentences within Set 1 are correct in a way the sentences within Set 2 are not.

Moreover, we can agree that Set 1 is correct whilst Set 2 is incorrect regardless of whether we think the sentences in Set 1 are true. Even the most staunch atheist would make a distinction between the two sets.

The sentences in Set 1 would be assessed as correct, unlike those in Set 2 (which might make it into the exam howlers list). Assessing something as correct can involve deeming it appropriate and relevant in the context of the RS classroom, taking it to be a proper thing to say within that context, judging it an adequate or good answer, awarding it marks, and so on. But this is independent of whether those uttering the sentences, or those assessing them, take them to be true. Suppose a teacher thinks that 'God is omnipotent' is not true because they believe there is no God. The teacher would nevertheless mark this as correct, as opposed to 'God lives in the sky', which they would mark as incorrect. A pupil who does not believe in Lord Shiva will take there to be no number of legs or arms Shiva really has, since really (they believe) Shiva does not exist. Yet there are still correct and incorrect things for this pupil to say about Shiva's legs. Even seemingly uncontentious sentences about human behaviour, like 'Many people in the world worship the Christian God', are not so straightforwardly true as they might seem, since there is extensive debate over whether so-called intentional attitudes (those attitudes which are about something or directed on something) require the existence of the thing they are about. Worshipping is an example of an intentional attitude, and if somebody's worshipping some thing $\mathrm{X}$ requires that there exist an $\mathrm{X}$ which is the thing they worship, then somebody who denies that $\mathrm{X}$ exists should also deny that anybody worships $X{ }^{2}$ Thus a disbeliever in the Christian God should not, at least not without further argument concerning intentionality, take the sentence 'Many people in the world worship the Christian God' to be true.

\footnotetext{
${ }^{2}$ For a recent introduction to this and related issues, see Sainsbury (2009).
} 
But they should surely consider it a correct thing to say in class, and no further argument about intentionality is needed to establish that. On the other hand, they will presumably consider a sentence like 'Many people in the world worship the Queen of England's teaspoons' an incorrect thing to say. Thus we can judge one sentence to be correct and the other incorrect whilst taking both to be untrue. These considerations point towards two apparent conclusions about correctness in the classroom. First, the correctness of a sentence in the context of the RS classroom is not determined by whether it is true or false. Neither can we establish that something is taken to be true on the basis of its being taken to be correct. Correctness and incorrectness are distinct from truth and falsity. Second, and relatedly, to judge a sentence to be correct in the classroom is not the same thing as believing that sentence. ${ }^{3}$

Note that there is no need for anybody in the class to take a particular sentence to be true in order for that to count as correct within the class. Take a classroom in which nobody subscribes to the religious view being studied; for example, a class where teacher and pupils are all Jewish and are studying Christianity. Even if nobody in the class, including the teacher, believes the sentence 'Three days after his death, Jesus rose from the dead' to be true, still this is a correct thing to say in class (unlike 'Three days after his death, Jesus went to the moon').

\footnotetext{
${ }^{3}$ The relationship between truth and correctness is of philosophical interest for a number of reasons. For example, we might debate whether the class of truth-bearers is different from the class of correctness-bearers - for instance, actions are naturally deemed correct or incorrect, but not true or false. This may lead us on to debates about fundamental ontology, concerning whether the structure of the world is fact-like or not. However, our present concern is more akin to recent debates concerning fictionalist approaches to various subject matters, which attempt to give ways of accommodating the things one wants to say without straightforwardly treating them as true. For a critical overview, see Caddick Bourne (2013).
} 
This leaves us with the question: what is correctness in the context of the RS classroom? As well as being philosophically significant in its own right, an answer to this question can inform how practitioners (such as teachers, examiners and education policy-makers) think about, justify and develop their practices. For it is an essential component of a complete understanding of what practices they are engaging in, and what commitments they are making when they endorse statements made in the context of the classroom. We shall set out two promising analyses of correctness and argue that, despite their initial plausibility, they face significant and telling challenges, before developing and defending an alternative position which explains correctness in terms of the functioning of an institution.

\section{The elliptical approach}

One possible solution to the puzzle is to say that sentences are correct because they are elliptical versions of a true sentence. For example, we might think that when the Jewish pupil says 'Three days after his death, Jesus rose from the dead', what she says is shorthand for 'Christians believe that three days after his death, Jesus rose from the dead'. ${ }^{4}$

This dissolves the problem of how one can take something to be correct without taking it to be true. The claim is that correct sentences have some tacit content which makes them true sentences.

\footnotetext{
${ }^{4}$ There are some contexts in which a question may be asked in the RS classroom which the elliptical approach is not designed to capture. A teacher may ask 'Did Jesus rise from the dead?' in a context in which what is required is for the student to explain their own beliefs and reflect critically on their reasons for these beliefs. Whilst correctness in that context is not our primary concern in this paper, the suggestions we make below (in 'The institutional approach') could (unlike the suggestions made by the elliptical approach) be extended to encompass what correctness amounts to in this context as well.
} 
Similarly, incorrect sentences have tacit content which makes them false. For example, 'Christians believe that three days after his death, Jesus went to the moon' is a false sentence, since Christians do not believe that three days after his death, Jesus went to the moon.

One way of supporting this account may be to note that sometimes prefixes are made explicit in class; a student might write or say 'Christians believe that...' in classwork or an exam, and questions are sometimes phrased accordingly (e.g. 'How would Christians respond to the ethical issue of care for the environment?'). These ways of explicitly setting the context for what follows - as concerning beliefs of certain people - might suggest that there is tacit context-setting going on even when we do not make such elements explicit. Additional support comes from cases where an assessor would take the addition of an explicit prefix to make no difference to how an answer should be judged. If 'Christians believe that Jesus rose from the dead' is assessed no differently from 'Jesus rose from the dead' in a certain context, that could lend support to the suggestion that the second is interpreted as having the same meaning as the first.

There is an immediate problem for the elliptical approach, however; specifying what the tacit prefix must be. 'Christians believe that' is underspecified - does it mean 'All Christians believe that', 'Some Christians believe that', or something else? The former is too demanding - many sentences which are correct in the RS classroom will be false if they are to be taken as saying that all Christians believe such-and-such. Assuming one can be a Christian and not believe in the literal truth of the Resurrection, 'All Christians believe that Jesus rose from the dead' can be false despite 'Jesus rose from the dead' being correct in a classroom context.

A possible response on behalf of the account is that anyone who does not believe that Jesus rose from the dead is not really a Christian. It might be said that subscribing to the Creed is an essential part of Christianity, and thus that anybody who does not have the beliefs laid out therein is not Christian. As a view of what Christianity is, this is contentious. Many people would think that there are sufficient conditions for being Christian which are not overridden by not believing that, say, Jesus 
rose from the dead. Take the case of Maurice Wiles, who rejects the idea of intervention by God in the world based on the argument that this would entail a partisan and selective deity (1993). The fact that he was a lifelong member of the Church of England, indeed, an ordained Anglican minister (in addition to having been Regius Professor of Divinity at Oxford), could be taken to be sufficient to make it irrelevant to his being a Christian whether he believed that Jesus rose from the dead.

In any case, there is another reason to reject the response that sentences such as 'All Christians believe that Jesus rose from the dead' are true by definition. Even if this were the case, it would not help us to account for judgements of correctness in the classroom. Plenty of teachers (and pupils) who judge 'Jesus rose from the dead' to be correct within the RS classroom do not take belief in the resurrection to be a necessary condition of being a Christian. Thus, their judgement that 'Jesus rose from the dead' is a correct thing to say cannot be explained in terms of their taking 'All Christians believe that Jesus rose from the dead' to be true. To explain judgements of correctness, this version of the elliptical approach would require that assessors of correctness in Religious Studies (teachers, examiners, etc.) believe the sentence 'All Christians believe that Jesus rose from the dead'; this is clearly too demanding. Moreover, even a teacher who does believe that belief in the resurrection is definitional of Christianity need not take this to be the basis for judging 'Jesus rose from the dead' to be correct in the classroom. Thus, to take the first sentence as elliptical for the second does not provide a plausible articulation of the standards of correctness within the classroom which practitioners are actually working with.

To overcome these difficulties, one might try moving to the less demanding reading of the prefix 'Christians believe that...', as 'Some Christians believe that...'. But this is so undemanding as to be too permissive. First, it does not distinguish between relevant and irrelevant beliefs held by some Christians. 'Some Christians believe that Monk is the greatest detective show' may be true, but this does not suffice for 'Monk is the greatest detective show' to be correct in the RS classroom. 
Second, even amongst relevant beliefs the prefix is too permissive. Some Christians believe that the formation of the Grand Canyon is down to the flood at the time of Noah. But 'The formation of the Grand Canyon is down to the flood at the time of Noah' would not be a correct thing to say in the RS classroom. What it would be correct to say is 'Some Christians believe that the formation of the Grand Canyon is down to the flood at the time of Noah'. But the fact that the sentence is correct when the prefix is explicit does not change the fact that it is incorrect when there is no such explicit prefix. It is this incorrectness which undermines the proposal that sentences which are correct in the classroom are correct because they are elliptical for true sentences of the form 'Some Christians believe that...'. If this were the reason for their correctness, it would also be a reason to take 'The formation of the Grand Canyon is down to the flood at the time of Noah' as correct, since this, too, is something some Christians believe.

This might prompt a defender of the elliptical approach to look for a middle way between these two renderings, construing the prefix as, say, 'Most Christians believe that...'. But this will not do either. Suppose relatively few Christians are aware that the miracles in John are signs that point to religious significance beyond the events, whereas the miracles in the Synoptic Gospels show divine power. ${ }^{5}$ Nevertheless, saying 'The miracles in John are signs that point to religious significance beyond the events, whereas the miracles in the Synoptic Gospels show divine power' would be correct in the RS classroom, and indeed something on which students could be examined at A Level, when studying John's Gospel. ${ }^{6}$

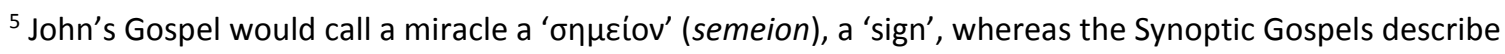

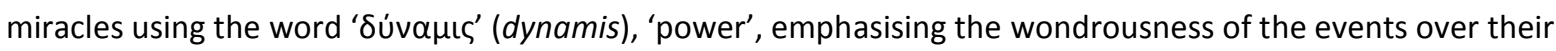
religious significance.
}

${ }^{6}$ A Levels are qualifications typically studied at age $16-18$ in the UK. 
We might try to avoid these problems by modifying the prefix to 'Many Christians believe that...'. Many need not be most - a minority may be many enough. Thus this version of the prefix gives us scope to avoid the problem of correct claims which most Christians do not believe because specialist study is required in order to form the relevant beliefs. At the same time, 'many' is slightly more demanding than 'some'. Nevertheless, this rendering of the prefix still falls foul of the problem of irrelevance. 'Many Christians believe that a cup of tea solves everything' may be true, but if it is that does not suffice to make 'A cup of tea solves everything' correct in the RS classroom.

Perhaps this shows that we should restrict ourselves to beliefs which many Christians hold but, further, which are acquired in the right sort of way - perhaps from a suitable representative of the religion, for example. Thus we might take sentences which are correct in the classroom as elliptical for something like 'Many Christians believe ... because a figurehead in Christianity said ...'. But this does not eliminate the problem of irrelevance. On July 13th 2013 the Daily Mail ran an article with the headline 'The Royal baby will be a drama. But what hope it will bring us, says Archbishop of Canterbury, Justin Welby'. If many Christians came to believe, on the basis of the Archbishop's comments, that the Royal baby will bring hope for the future, that still does not suffice to make 'The Royal baby will bring hope for the future' correct in the RS classroom. (Notice that this is also an argument against taking the prefix to be simply 'Figureheads in Christianity believe...'. ${ }^{7}$

\footnotetext{
${ }^{7}$ In response to the problem of irrelevance, we might construe the elliptical approach as an account of the difference between a relevant sentence which is correct and a relevant sentence which is not correct. On this construal, the approach would be putting forward a candidate necessary condition of correctness, but would not be offering a sufficient condition, since relevance is a further prerequisite of correctness. Another way of putting this is to say that it is relevance which determines which of all the true sentences bearing the prefixes in question correspond to sentences which are correct in the classroom. But then the elliptical approach gives us at best part of the story about correctness, since it leaves untouched the question of what makes a
} 
In any case, classroom discussion of perfectly relevant matters also creates problems, if we take correct sentences to be elliptical for true sentences beginning 'Many Christians believe that...' Consider this exchange:

Student 1: What is the Shroud of Turin?

Student 2: It's the cloth Jesus was buried in.

Teacher: Wait a minute. It's not entirely clear what the Shroud of Turin is.

Student 2: But many Christians believe it's the cloth Jesus was buried in.

Teacher: Yes, that's true. But there are also many Christians who reject that claim.

The teacher's point is that it is true to say both 'Many Christians believe that the Shroud of Turin is the cloth Jesus was buried in' and 'Many Christians believe that it is not the case that the Shroud of Turin is the cloth Jesus was buried in' - indeed, that we should say both if we are to give an accurate picture of how things stand on this issue. Many RS GCSE questions are geared towards exactly this kind of response, with students often being encouraged to compare opposing perspectives within Christianity. ${ }^{8}$ It certainly would not be correct, though, for the student to write in their essay 'The Shroud of Turin is the cloth in which Jesus was buried. The Shroud of Turin is not the cloth in which Jesus was buried.' Thus the truth of both prefixed sentences cannot suffice for correctness of the

sentence relevant. It will not do to respond that correctness is one thing and relevance is quite another. The connection between the two is more intimate than that, as evidenced by the fact that a teacher may legitimately state 'This is irrelevant' as a justification for, say, not awarding a student any marks for an answer. One advantage of the positive account we shall propose (in 'The institutional approach', below) is that it suggests a more unified and integrated approach, explaining the distinction between what is correct and what is not in terms which can also be used to characterise the distinction between what is relevant and what is not.

${ }^{8}$ GCSEs are qualifications typically studied at age $14-16$ in the UK. 
apparently unprefixed sentences in the classroom: the prefixed sentences are true, whereas to utter the two apparently unprefixed sentences together would be judged not just incorrect, but borderline nonsense. This shows that this is not simply a case where the prefix 'Many Christians believe that...' is not made explicit, but rather, a case where no such prefix is tacit either.

This illustrates that even seemingly relevant beliefs which many Christians hold do not always translate into sentences which would be assessed as correct in the RS classroom. Interestingly, it would be correct to say 'There is new evidence that the Shroud of Turin could be around 2000 years old.' The discovery of this evidence made the BBC news, so we could expect that many Christians are aware of it. In that case, both 'Many Christians believe that there is new evidence that the Shroud of Turin could be around 2000 years old' and 'Many Christians believe that the Shroud of Turin is the cloth in which Jesus was buried' would be true. Thus appealing to the prefix 'Many Christians believe...' offers no explanation of why 'There is new evidence that the Shroud of Turin could be around 2000 years old' is correct in the classroom while 'The Shroud of Turin is the cloth in which Jesus was buried' is not. Further, 'There is new evidence that the Shroud of Turin could be around 2000 years old' would be correct regardless of whether its prefixed version is true. Had the new evidence been less widely reported, even to the extent where no Christian is aware of it, a student who said 'There is new evidence that the Shroud of Turin could be around 2000 years old' would not only be saying something correct, but would merit praise for their extra research.

We have argued that prefixes like 'All Christians believe...', 'Most Christians believe...', 'Many Christians believe...' and 'Some Christians believe...' do not succeed in providing an analysis of correctness in the RS classroom. ${ }^{9}$ Nevertheless, their relevance in the classroom should not be

\footnotetext{
${ }^{9}$ Neither, we suggest, will the prefix 'Traditionally, Christians believe that...', which was suggested by an anonymous referee. An attempt to explicate what this prefix means, in a way which incorporates what is correct in the classroom while excluding what is not correct, will take us back to many of the same problems
} 
overlooked. As the exchange above shows, one way in which somebody might explicitly use such locutions is in an attempt to persuade others of the worth of their contribution. Student 2 points out that many Christians believe the Turin Shroud to be the cloth in which Jesus was buried partly to justify his original contribution ('It's the cloth Jesus was buried in') as having made a worthwhile contribution to class discussion.

This reinforces our argument that tacit prefixes are not part of the meaning of correct sentences. If they were, then the student would not be saying anything new by adding explicitly that 'Many Christians believe' what he or she made explicit the first time around. Rather than providing new information to justify his or her original contribution, the student would be providing a redundant reiteration of the original contribution.

Moreover, the material actually covered in RS seems not to be chosen based on representing exactly what is in fact practised or believed by particular people. While the material chosen does engage with traditions, this cannot simply be reduced to an attempt to represent how people really practise or engage with these traditions. A good example of this is the teaching in UK schools about the role of the Mikveh, a Jewish ritual bath, which has fallen out of use after menstruation amongst most Jewish women in the UK. Students would be assessed as correct if they talked about the role of the Mikveh, irrespective of the proportion of Jews for whom this is part of their religious practice. 'The Mikveh is a ritual bath' would be correct, despite the fact that 'Many Jews use the Mikveh, a ritual

for the elliptical approach which we have already identified. If we understand a tradition to be the transmission of beliefs and practices from generation to generation, then whose beliefs must be transmitted, and how many in the next generation must have a belief for it to count as having been transmitted? How are we to demarcate a tradition in order to exclude beliefs which are irrelevant? This is not to overlook the importance of perceptions of what is traditional to determining what is correct in the classroom, as we discuss in 'The Institutional Approach', below. 
bath' might in fact be untrue. Some ${ }^{10}$ might contest that RS wrongly ignores the diversity of actual religious practice, but nevertheless, this example is enough to demonstrate that correctness as it actually is assessed in the RS classroom comes apart from anthropological claims about how many people believe or practise certain tenets or customs of their faith.

The imaginative approach

The elliptical approach attempts to explain correctness of sentences in terms of corresponding sentences which are believed to be true. Perhaps a more fruitful approach would be to abandon the idea that correctness in the classroom can be boiled down to truth, and focus instead on something different - imagination.

Kendall Walton has given an influential explanation of fiction in terms of games of make-believe. Certain things are true in a game in virtue of what its players do and what their environment is like. Take Walton's example of a game in which we pretend to be in a bear-inhabited forest (1990 ch.1). We stipulate that tree-stumps are to count as bears. Wherever there is in actuality a stump, in the game there is a bear. The tree-stumps are 'props': bits of the actual world which call for the gameplayer to imagine certain things (in this case, that there is a bear).

According to Walton, fictions are props which make certain things fictional according to the game played by the audience-member. Sentences of novels, poses of actors on stage, etc., prescribe that

\footnotetext{
${ }^{10}$ Such as Robert Jackson's approach which 'takes a critical stance towards Western, post-Enlightenment models of representing world religions as homogeneous belief systems, whose essence is expressed through set structures and whose membership is seen in terms of necessary and sufficient conditions.' (2011:191)
} 
the audience-member imagine certain things. For it to be fictional that $p$ is for there to be a prescription to imagine that $p$.

One potential way to address the puzzle of correctness is to extend the idea of games of makebelieve to the RS classroom, making RS a game in which teachers and students imaginatively engage with certain worldviews. ${ }^{11}$ The reason for this move is that it allows us to replace the appeal to truth with an appeal to 'truth in the game'. It is true in the game that three days after his death, Jesus rose from the dead, and this is what makes it correct to say 'Three days after his death, Jesus rose from the dead' in the RS classroom. ${ }^{12}$

${ }^{11}$ We do not wish to suggest that Walton would himself endorse this extension. Other examples of extensions of Walton's idea of games of make-believe to attempt to understand areas beyond fiction include applications to mathematical discourse (e.g. Leng (2010)) and to the use of models in science (e.g. Toon (2010)).

${ }^{12}$ Some may balk at the use of the word 'game' to describe what is going on in the RS classroom. To mitigate this, it should be noted that the term 'game of make-believe' is drawn from Walton's canonical work on imaginative engagement. What it indicates is that the project one is engaged in, in the RS classroom, is centrally one of imagining. Certain connotations which the word 'game' may have in other contexts should be suspended. For example, to say participants in the RS classroom are engaged in a 'game' in this sense is not to say that they are doing something the purpose of which is entertainment, nor is it to say that they are not taking seriously the worldviews or ideas with which they are imaginatively engaging. It also leaves open questions about how the game is to be played - for example, whether certain types of imagination, such as empathy, play a special role. Thus the term 'game' should not diminish the seriousness with which the imaginative approach takes the practice it attempts to characterise. (Likewise for the other extensions of Walton's account mentioned in footnote 11, above.) However, it would be open to a defender of the imaginative approach who dislikes the term 'game' to replace it with another - perhaps 'imaginative project', for instance - while retaining the same account of what participation in the RS classroom involves. 
Note that being true in a game is not in conflict with being true in actuality. It is true in the game played with the Sherlock Holmes stories that Baker Street is in London - and, of course, Baker Street actually is in London. Relatedly, making utterances as part of a game does not require taking them to be false. A pupil participating in the game who says 'Three days after his death, Jesus rose from the dead' might also believe the sentence to be true. ${ }^{13}$ But it seems the pupil does not have to believe the sentence 'Three days after his death, Jesus rose from the dead' in order to utter it as part of playing the game of make-believe. Thus whether something is correct, according to this view, is independent of whether or not it is believed.

This allows the imaginative approach neatly to sidestep many of the concerns with the elliptical approach. Although playing the game calls for us to engage imaginatively with certain worldviews, truth in the game is not analysed in terms of who believes, or how many people believe, whatever content that worldview might have. Thus we avoid the problems, noted above, posed by irrelevant beliefs, minority beliefs, and beliefs about obscure matters.

The imaginative approach also sits well with what appears to be going on when students fail to engage in the RS classroom, or, indeed, are offended by being asked to engage. Consider a case in the RS classroom where God's eternity is a point of discussion, and a student's contribution is 'God

\footnotetext{
${ }^{13}$ Indeed, there are cases where taking part in a game of make-believe has been deemed inappropriate for those who cannot be expected to believe what content it may have - as in those schools who have opted for secular Christmas plays over Nativity plays because they are secular establishments. We shall not explore in detail how closely the inappropriateness is related to the imaginative activities of the players. Some may deem the Nativity play inappropriate precisely because it would call for some pupils to imagine certain things which they do not believe. There may also be other factors, such as the fact that portraying the son of God could be regarded as blasphemous by some members of the school, or that Nativity plays are simply not part of the culture of all members.
} 
doesn't exist', beyond which the student refuses to engage further. On the imaginative approach, this might be described as a case of 'imaginative resistance', where there is a block to somebody's imagining what they are being asked to imagine because they find it difficult to do so. Imaginative resistance might arise where somebody cannot imagine what they are being asked to, perhaps because they cannot make sense of it. Or it might arise where somebody does not want to imagine what they are being asked to, and thus finds it difficult to bring themselves to engage. For example, a student who thinks a worldview is silly or pernicious may resist playing a game in which that worldview is true. ${ }^{14}$

Another appealing feature of this approach is that, whilst the elliptical account of correctness encouraged us to take each sentence on a case-by-case basis, considering whether it is believed by certain people, the imaginative approach is holistic, treating individual sentences as situated within the narrative of the whole game. Just as individual beliefs have a place within a worldview, individual utterances in the RS classroom have a place within the larger game.

This also allows us to make better sense of the correctness of inferences in the context of the classroom. Students studying resurrection narratives could infer from the story of Jesus's resurrection that, in Christianity, resurrection of the body is possible. Similarly, they might infer from 'moksa is the release of the soul' that, within the Hindu worldview, there is a soul. Asked to describe Christian or Hindu understandings of life after death, it would be correct for the student to say 'there is resurrection of the body' or 'there is a soul', respectively. The student could be confident

\footnotetext{
${ }^{14}$ Whilst the imaginative approach therefore has resources to articulate what might be going in some cases of disengagement, this is not to say that other approaches could not also be developed to account for disengagement.
} 
saying these things because of the inferences they have made from other sentences which they know to be correct in the classroom.

A good account of correctness needs to allow for, and make sense of, this. Here the elliptical approach would be of little help. If the correctness of an individual sentence is to be judged by the truth of an appropriately related prefixed sentence, the process of inference becomes one of hypothesising about what people are likely to believe given the prevalence of other beliefs.

For instance, take the student who has learnt about the resurrection of Jesus and, based on this, says during a lesson on Christianity that the body can be resurrected. According to the elliptical approach, this is correct because it is true that certain people believe that the body can be resurrected. Yet it is often unnatural, we think, to describe the inference as an inference from one prefixed sentence to another - e.g. from 'Many Christians believe that three days after his death, Jesus rose from the dead' to 'Many Christians believe that the body can be resurrected'. The inference is from the correct sentence:

i) 'Three days after his death, Jesus rose from the dead'

to:

ii) 'The body can be resurrected'.

This is quite different from the kind of inference which would take us from (i) to (ii) if they were construed as the elliptical approach proposes, namely, from:

iii) 'Many Christians believe that three days after his death, Jesus rose from the dead' to:

iv) 'Many Christians believe that the body can be resurrected'. 
One important difference is in what goes into establishing whether the inference is a good one or not. The standards for the inference from (i) to (ii) are, plausibly, deductive. We are concerned with whether the conclusion follows from the premise, in the sense that the truth of the premise would guarantee the truth of the conclusion; the student perhaps reasons that for Jesus to rise from the dead was for a body to be resurrected, therefore, the body can be resurrected. But in the case of the inference from (iii) to (iv), it is far from clear that the truth of the premise is enough to guarantee the truth of the conclusion - maybe it is perfectly possible, even if unlikely, for many Christians to believe that three days after his death, Jesus rose from the dead without it being the case that many Christians believe that the body can be resurrected. Whether the inference from (iii) to (iv) is a good one depends on whether, as a matter of fact, the first premise would make the second more likely to be true. Putting it another way: for the inference from (iii) to (iv) to be deductive, another premise would have to be assumed: that Christians believe the consequences of their beliefs. And to support this premise would require either extensive empirical research (or, if not that, extensive epistemological theorising), neither of which seems to be the basis on which the inference from (i) to (ii) could be made in the context of the RS classroom.

This points to another crucial difference, namely, the fact that moving from (iii) to (iv) relies on social or anthropological considerations. If it were the inference to and from prefixed sentences which mattered, then methods of inference in the RS classroom would be very different from those actually used. For example, students might have to study psychological and statistical data about believers. This does not capture what is in fact their project, namely, piecing together the elements of religious worldviews to form a whole.

Inference has a place in a game of make-believe; what is true in the game is often determined not just by things we are told explicitly, but by what can be inferred. From the premise that Sherlock Holmes lives in 221B Baker Street, together with the assumption that he has only one dwelling, we can infer that Holmes does not live in 221A Baker Street. In the same way, games of make-believe 
are amenable to the inferences actually made in the context of the RS classroom. Unlike the elliptical approach, the imaginative approach does not constrain the variety of bases on which correct inferences may be made.

Suppose some students learn that the Sikh holy text is called the 'Guru Granth Sahib' because it is seen to be a teacher of the faith, hence a Guru. In the course of studying Sikhism, they then come across Guru Nanak. They can then incorporate imaginings concerning the role of Guru Nanak into their game in a way which fits with what they have been imagining so far, inferring that Guru Nanak was also a teacher of the faith. Or suppose a student, having made-believe when learning about Christianity that there is a time at which the trumpet shall sound and the dead shall be raised, writes in an exam answer 'the dead shall be raised'. This sentence is entailed by 'there is a time at which the trumpet shall sound and the dead shall be raised', and, while it might be judged as only demonstrating partial understanding of Christian eschatology, would nevertheless be considered correct.

Nevertheless, whilst it provides a framework which makes space for the role of inference in the classroom, the idea of make-believe does not, in itself, give us any positive account of what the constraints on correct inference are. This begins to reveal the explanatory limitations of the imaginative approach. It tells us that games are being played, but gives us no insight into their scope or how their rules are established.

Perhaps the most intuitive approach would be to say that games of make-believe played in the RS classroom correspond to the religions being studied - in studying Judaism, for example, students are playing the 'Judaism game'. This might naturally reflect what often happens in the RS classroom, where each religion tends to be taught in turn rather than together, with a term or semester playing the 'Judaism game' being followed by a term or semester playing the 'Islam game'. 
But if games of make-believe are to be understood as corresponding to a particular religion, the imaginative approach faces potential difficulties concerning comparisons and identifications made between elements of different religions in the RS classroom, and the inferences these comparisons and identifications can give rise to. Take the example of a class studying the role of prophecy in Islam, in which a student might say 'The Prophet Isa is the same person as Jesus Christ'. Such a contribution cannot be understood as belonging entirely to the 'Islam game', nor entirely to the 'Christianity game'. How, then, is the student's contribution to be construed by an approach which takes students in the RS classroom to be participating in games of make-believe?

Two options suggest themselves. The first is to say that the student is taking an external perspective which notes similarities between different games, both of which can be played in the classroom. Their comparison should be understood as making an observation along the following lines: what one is prescribed to imagine when playing elements of the 'Christianity game' is similar in certain respects to what one is prescribed to imagine when playing elements of the 'Islam game'. One consequence of this approach is that there is a discontinuity in what we should take people to be doing when uttering sentences in the classroom. In a single conversation - perhaps even a single sentence - a student may move between participating in games and commenting on what participation in those games involves.

Those who prefer to think there is more unification in how classroom contributions are to be construed may prefer the second option, which is to attempt to incorporate comparative and noncomparative utterances within a single imaginative enterprise by holding that one game can draw in elements from the different religions being considered. But delineating the content of such a game, and the inferences which may legitimately be made within it, is not a straightforward matter. For example, the religions being compared may contradict each other in places, and so we must account for what systems of inference are properly used when navigating contradictory elements within a single game. 'Jesus did and did not rise from the dead' is not necessarily a correct contribution in a 
classroom context where 'The Prophet Isa is Jesus' is correct, yet we may legitimately infer the former from the latter if we import information about the Prophet Isa and the Christian Jesus into the same game and take the rules of the game to be given by classical logic. A version of the imaginative approach in which a single game takes elements from different religions must either place well-motivated restrictions on what elements of the religion are to be imported, or explain what (non-classical) system of inference is appropriate to the game.

\section{The institutional approach}

The imaginative approach has not been conclusively ruled out by the problems we have raised. But the challenge for such an approach is to define precisely what a game of make-believe in the RS classroom involves; simply saying that correctness amounts to 'truth in a game' does not achieve this. Perhaps further characterisation of what precisely the game of make-believe comprises could be successful; we do not wish to rule this out. (Neither do we wish to rule out that the elliptical approach could be made to work, though it would require significant development.) However, we think there is a more direct, more intuitive and more informative route through the problem of correctness.

The limitations of the elliptical and imaginative approaches should remind us of what is wanted from a good account of correctness in the RS classroom. The account should explain the difference between a sentence which is correct and one which is not. It should explain why judging something to be correct is distinct from judging it to be true. In order to do either of these things in a compelling way, it must also explain where the criteria of correctness come from. Our proposal is that the criteria come from a practice: that of teaching, studying and assessing RS in schools. By placing the emphasis on the practice itself, we can improve on the elliptical approach by adequately capturing and explaining judgements of correctness, and improve on the imaginative approach by 
unifying an answer to the question of what makes correctness different from truth with an identification of which particular context fixes the criteria of correctness.

The starting point of our account is to look at what happens in the RS classroom. Imagine this exchange:

Teacher: What attributes does God have? Let's make a list on the board.

Student: Omnipotence?

Teacher: Yes, absolutely right. What does that mean?

Student: God is all-powerful.

In this exchange, the student's contributions are correct. When he writes them in his homework, he will be credited. From this, he will know that these are the kinds of contributions to prepare for his exams. Throughout this process, it is the teacher who judges the student's contributions to be correct.

Nevertheless, the teacher's judgement cannot suffice for correctness, since we all accept that it is possible for teachers to go wrong. For example, if a teacher tells a student that the 'yad' is used as a pointer when reading the Torah because to touch it directly would be sacrilegious, they would be saying something incorrect, as the 'yad' is used rather for the practical maintenance of the scrolls. The teacher plays a part in a wider community which self-regulates, brings together expertise and shares resources in order to keep its members informed. The criteria of correctness therefore go beyond what any one individual judges - or rather, in some cases, misjudges - to be correct.

This community, together with its practices and ways of interacting, we will refer to as the 'RS institution'. The institution includes teachers and examiners (of course, some individuals will have both roles). It contains academics who train RS teachers and undertake research in the area. It also includes members of the religious groups which inform how teachers and examiners construct 
syllabuses, and what is deemed relevant. In the UK, Standing Advisory Councils for Religious Education (SACREs) play this role, chaired by local advisors, employed by local government.

Students themselves are of course also a part of this institution: they play a part in judging the correctness of their peers' contributions, and could object where a teacher has gone wrong. Students could also contribute something to the debate, such as a particularly illuminating example, which is absorbed into how the teacher approaches that topic in future years. It is also true that the way a topic is approached will depend on student engagement, and as such, students shape both what the subject is and what it will be. For example, in the days when there was a greater scriptural emphasis in how religion was studied in schools, it would not have counted as correct in the RS classroom to say 'because of science, religious faith is on shaky ground', but now, because of student interest in Philosophy of Religion, these questions are entertained much more. Indeed, it would now be a commonplace thing to utter in the RS classroom and in the right context would get a mark, especially if the point was sufficiently justified.

Religious traditions are clearly central to what is going on in the RS classroom. They provide much of the subject matter to be discussed. The role of members of faith groups in the institution is therefore very important. That said, whilst what is correct in the RS classroom is informed by the content of religious traditions existing independently of or externally to the institution, there is no direct route from what is practised, believed or accepted as part of a tradition to what is correct in the classroom (i.e. correctness cannot simply be boiled down to 'being part of a tradition'). One reason for this (noted above in footnote 9) is that it is problematic to give an analysis of what it is to be 'traditional' or 'part of a tradition' which corresponds well enough to just what we are looking for from the notion of correctness. A more important reason here, however, is that practitioners in the RS institution provide a filter, taking information from these traditions (including their own, in some 
cases) and selecting and construing it in a way they deem pedagogically suitable. ${ }^{15} \ln$ the teaching of Christianity, devotional mantras such as 'Jesus is my personal friend and saviour' would not be eligible to be judged correct or incorrect, and should therefore be taken to be irrelevant, even if they happen to express sentiments held dear by the teacher.

Practitioners also make additional judgements about how to present the filtered information to students of the age and the expectations they cater to. For example, a comparison of the Trinity with a shamrock from a five-year old might be welcomed, because it reflects what the institution takes to be important to this topic, namely the idea of three things and yet one thing. As a suggestion from a student in their late teens, the comparison still focuses on the main issue, but perhaps someone of this age would be expected to provide a more complex reflection on the Trinity.

There is considerable debate within the institution about what it would take for the 'filter' to function in an acceptable and productive way. We might call to mind Liam Gearon's observation that 'in no other subject do the aims and intentions that underpin the subject vary so greatly' (2013: 50).

Gearon identifies six different paradigms for pedagogy in Religious Education, each with different methodologies, outlook, modes of assessment and, importantly, aims. ${ }^{16}$ Whereas some put an aim of moral development at the centre of the subject, others prioritise a search for truth. Some want religions to be understood and experienced as though from within. For some, learning about religion

\footnotetext{
${ }^{15}$ Pedagogy is of course an important part of any tradition, as without it, the tradition will die. This confessional religious instruction is to be distinguished from the practice of the RS institution, however. The RS institution might make use of certain simplifications or examples used in the confessional teaching of the faith, but filters which examples would be appropriate for the RS classroom.
}

\footnotetext{
${ }^{16}$ 1. Scriptural-theological; 2. Phenomenological; 3. Psychological-experiential; 4. Philosophical-conceptual; 5. Socio-cultural; 6. Historical-political
} 
is a means to an end, such as tolerance in society. The different paradigms can be understood as different ways of 'filtering'. The presence of these different paradigms reflects in part the fact that there are differences within the institution in what people find interesting, such as texts, anthropology of religion, developments in religious history, or particular religions over others.

But debate over what the aims of the institution are does not show that it is not an institution. For these debates take place within the RS institution, between its members. Debate, even disagreement, is part of the normal healthy functioning of the institution, allowing for constant selfevaluation and renewal. Because the RS institution is a network of persons, related to each other in various ways, it is no surprise that an uncontentious statement of its aims cannot be given, since they cannot be reduced to the aims of any one individual. As such, these observations lend support to an institutional understanding of correctness.

In addition to the fact that practitioners may disagree over what the aims of RS are, the RS institution is also constrained by external factors. Governments dictate to a significant extent how the RS institution functions, imposing curriculum content or assessment criteria, for example. Of course, governments also have the power to preclude state-funded schools to teach Religious Studies, such as in the cases of France and the US. International bodies will also exert pressure on governments to achieve certain aims in schools, the Toledo Guiding Principles (OSCE (2007)) and the REDCo project (see Weisse (2010)) being good examples of this. These colour what is expected of the institution, and may influence - rightly or wrongly - what RS does to justify its place on the curriculum. Citizenship and tolerance have been high priorities for bodies outside the RS Institution in recent years (something which a number of studies, e.g. Gearon (2013) and Erricker (2013) trace back, in part at least, to 9/11). As such, external bodies have an indirect impact on what is correct in the classroom. Nevertheless, this does not mean the institution is simply being dictated to. We should not underestimate the extent to which creative adaptations to these requirements can occur within the institution. Neither should we overlook the ways in which the institution can be formative 
of policy through dialogue. Moreover, in the UK, subject specialists are employed to represent both government and the RS institution in creating 'agreed syllabuses' as benchmarks of best practice in the subject.

Whatever internal conflict exists, and however external pressures change the institution, there is enough unity in the way the institution functions to give us some grip on the idea of what proper 'filtering' looks like. The institution imposes certain expectations and experiences on some of its new representatives, such as trainee teachers, because it takes these to be a means of learning how to 'filter' information about traditions and how to form and navigate classroom discourse in such a way that students acquire what the institution wants them to acquire. These training processes (which are not limited to formal qualifications, but include informal, on-the-job training) serve to equip people to judge, fairly reliably, what is correct in the classroom - i.e., what the institution is currently prepared to treat as correct. It is a feature of the practice of the institution, for example, that being an advocate for a tradition is not sufficient to teach it in the context of the RS institution. The way the institution functions also makes it the case that subject knowledge is necessary, but not sufficient, as it may not be enough to satisfy others of the institution's aims, e.g. of promoting pupils' understanding of religions, something which requires further communicative skills.

The key to correctness of judgements is the quality of judges. The RS institution invests considerable effort in procedures to regulate how good its teachers and examiners are as judges of correctness. Review processes, such as moderation of coursework, 'seeding' of examiners' marks, and the right to appeal to a chief examiner play an integral part in this. (Moderation serves both to assess particular judges, as well as ensure parity over a cohort of judges.) Even following a nationally examined syllabus itself plays a part in regulating practice in the classroom.

The standards of correctness for sentences uttered in the context of the RS classroom are not independent of the training processes designed to enable teachers to recognise those standards. To an extent, what is correct is determined by what is recognised as correct by those who have 
undergone the relevant training. This is not the whole story, since the institution can question and adjust its training process if they do not generate certain judgements of correctness which the institution had a prior commitment to. But it would be artificial to suggest that the standards of correctness can be catalogued independently of describing the training processes which lead to judgements of correctness. Rather, the two help to construct one another. This is not a worrisome circularity, but a bootstrapping typical of living, breathing practices. The institutional approach does not have as a consequence that 'anything goes' when it comes to correctness. The standard of correctness is internal rather than external, which is quite different from there being no standard at all.

None of this means, of course, that correctness and truth are in tension with each other. There is no need to say that 'Khalsa Sikhs wear turbans' is not correct because it is true. Indeed, we can allow that, in this case, its truth has much to do with why it is correct. The RS institution is, after all, interested partly in reflecting facts about how religion is practised. That the functioning of the institution cannot be reduced to this aim does not mean that this aim plays no role in determining what is to be judged correct.

At the same time, the institutional approach goes some way towards assuaging an anxiety about talking in terms of truth, whether stemming from post-modernism, from concerns for political correctness, or from elsewhere. This anxiety also has a practical, pedagogical consequence: a worry about talking in a way which amounts to asserting the truth or falsehood of religious doctrines in the classroom. Our account should be welcomed by those who have such concerns, though it does not rely on them. RS professionals can teach secure in the knowledge that articulating robust criteria of correctness for the subject does not rest on taking its subject matter to be true.

Our view that the correctness of a judgement is constituted by its being the kind of judgement that a good judge would make is reminiscent of Hume's treatment of aesthetic judgements in 'Of the Standard of Taste'. Both root the idea of a correct judgement in a description of how a practice 
functions - in Hume's case, art criticism, and in our case, the RS institution - and what expectations of judges characterise that practice. Indeed, we can see the examples we have given as mapping on to some of the criteria Hume gives for good judgement, particularly practice, delicacy and lack of prejudice. Training can be seen as the RS institution's way of ensuring that judges meet the condition of practice by giving them relevant experience of the material which they are to judge and the context in which they are to make such judgements. Training also involves inculcating some of the other virtues of the good judge, such as delicacy - an ability to judge in a comparatively nuanced and fine-grained way where others may see only the obvious. A teacher who tells students simply that kneeling is a 'holy thing' to do fails to attend, in making her judgement, to more specific and subtle features of the act she is talking about.

The Humean standard of lack of prejudice may be particularly pertinent in the RS classroom. Note that to be 'prejudiced' in this case is not necessarily to exhibit bigotry, but to have your judgement clouded by your own point of view (regardless of the moral status of that point of view). Hume identifies two types of prejudice in the case of art criticism: that which comes from a particular perspective, such as geographical location or period in time, and that which comes from having a personal stake in propagating a certain view (e.g. a critic's positive judgement tends not to be taken seriously if they are set to profit financially from the success of an artist). The RS institution, similarly, expects its judges to be able, as much as possible, to understand a practice in terms of its place in a worldview to which it belongs, rather than to fail to comprehend it because it has no place in the worldviews familiar from the cultural setting which the practitioner knows. This does not mean a good judge should be somehow perspective-less, entirely without situation or context. This would not be a reasonable demand of human beings. What is taken to be a reasonable demand is that judges should have a kind of openness, the lack of which amounts to a kind of imaginative failure. Take, for example, a teacher who is unable to convey the subtlety of Hindu ideas about God because they see these ideas only as a denial of the monotheism with which they are familiar. The RS institution also expects its judges to act on the interests of the institution rather than out of their 
own personal interests. For example, an aim of getting more young people to Church on Sunday, or 'winning souls for God', would be regarded as compromising a teacher's judgement were it to govern what they cover or what marks they award in the classroom.

One prospective objection to Hume's approach to aesthetic appreciation is that it leaves judgements of taste ultimately ungrounded. A parallel objection might, then, be made to the institutional approach to correctness. Does it make correctness an arbitrary matter, allowing the institution to deem whatever it likes correct without deferring at all to the world beyond it? Having given an account of who the judges of correctness are, does it still leave hanging the question of what the basis of their judgement is? To answer these objections in full would require more space than we have here, but we can gesture at what we take to be the right solution. Rather than taking an appeal to practitioners (whether members of the RS institution or members of the institution of art criticism) to push back the question of the basis of their good judgements, we should take it as undercutting that question by replacing an emphasis on the truth of a judgement with an emphasis on the practice of judging. The question 'What do we require of a judgement in order to endorse it?' becomes the question 'What do we require of a judge in order to trust them on this matter?'.

While it is an expectation of judges that they should, for the most part, be able to give reasons for the particular judgements they make, the strategy we are endorsing suggests that none of these reasons translates into a general account of correctness, which is instead to be found in what skills we, as a matter of fact, expect from another person if we are to give them credence. As such, an institution is not immune from outsiders' appraisals. If the skills it demands from its representatives are found not to match the skills we expect them to have - if, for example, the RS institution allowed practitioners to judge correctness in a way which lacked the virtue of delicacy - it will be challenged. Many institutions have the possibility of challenge built into their structure through mechanisms for external regulation, and, as noted, the RS institution is formally constrained by external factors. But, 
as with other institutions, it is also vulnerable to the informal constraint that an institution can become unsustainable, and its standards disallowed, if public dissatisfaction is strong enough.

There is much more to be said in fully developing and defending the institutional approach. We hope at least to have shown that it is worthy of development. The institutional approach tells us how to deal with the original question 'How do you assess that?'. It addresses this in the same way it will address the question of what falls within the scope of RS. To answer either question, we look to what the practitioners are doing. Just as we would, to find out what counts as mathematics, what counts as philosophy, what counts as dressage. Whether we endorse the practice and want it to continue is a further question. This approach explains only that there are standards, if the practice exists. The practice of RS can, indeed, be problematized by realising that it involves judging something to be correct regardless of whether it is believed to be true. But this problem is solved or rather, dissolved - once we think of correctness not as correspondence to a set of standards external to the practice, but rather as arising from that practice. Once correctness is seen as internal to the practice, then, by explaining how an institution functions, we also specify the basis of its criteria of correctness. ${ }^{17}$

\footnotetext{
${ }^{17}$ The authors would like to thank two anonymous referees for their feedback.
} 
Bibliography

CADDICK BOURNE, EMILY (2013) 'Recent Work on Fictionalism' in Analysis Reviews, 73.1, pp.147-162

ERRICKER, CLIVE (2013) 'The Global Context of Religion and Belief', in: M. CHATER \& C. ERRICKER

(ed.) Does Religious Education have a Future? Pedagogical and Policy Prospects, pp.11-25 (Abingdon, Routledge)

GEARSON, LIAM (2013) MasterClass in Religious Education: Transforming Teaching and Learning (London, Bloomsbury)

HUME, DAVID (1777) 'Of the Standard of Taste' in his Essays and Treatises on Several Subjects (London, A.Millar; Edinburgh, A.Kincaid \& A.Donaldson)

JACKSON, ROBERT (2011) 'Religion, Education, Dialogue and Conflict: Editorial Introduction' in British Journal of Religious Education, 33.2, pp.189-208

LENG, MARY (2010) Mathematics and Reality (Oxford, Oxford University Press)

OSCE (2007) Toledo Guiding Principles on Teaching About Religions and Beliefs in Public Schools (Organization for Security and Co-operation in Europe, Office for Democratic Institutions and Human Rights), http://www.osce.org/odihr/29154?download=true, accessed 29 September 2015

SAINSBURY, R. M. (2009) Fiction and Fictionalism (London, Routledge)

TOON, ADAM (2010) 'Models as make-believe', in: R. FRIGG \& M. HUNTER (eds.) Beyond Mimesis and Convention, Boston Studies in the Philosophy of Science, 262, pp.71-96 (Dordrecht, Springer)

WALTON, KENDALL L. (1990) Mimesis as Make-Believe (Cambridge, Mass.: Harvard University Press) WEISSE, WOLFRAM (2010) 'REDco: A European Research Project on Religion in Education', in Religion and Education, 37.3, pp.187-202 
WILES, MAURICE F. (1993) God's Action in the World: The Bampton Lectures for 1986 (London, SCM Press) 